\title{
Life Course models of socioeconomic position and cardiovascular risk factors: 1946 Birth Cohort
}

\author{
Emily T. Murray, Ph.D. ${ }^{1,2}$, Gita D Mishra, Ph.D. ${ }^{1}$, Diana Kuh, Ph.D. ${ }^{1}$, Jack Guralnik, Ph.D. ${ }^{2}$, \\ Stephanie Black, M.Sc. ${ }^{1}$, and Rebecca Hardy, Ph.D. ${ }^{1}$ \\ ${ }^{1}$ MRC Unit for Lifelong Health and Ageing, University College and Royal Free Medical School, \\ London, United Kingdom \\ ${ }^{2}$ Laboratory of Epidemiology, Demography, and Biometry Gateway Building, Bethesda, MD, USA
}

\section{Abstract}

Purpose-To identify the life course model that best describes the association between life course socioeconomic position (SEP) and cardiovascular (CVD) risk factors [body mass index (BMI), systolic and diastolic blood pressure, total cholesterol, low-density lipoprotein, highdensity lipoprotein, triglycerides, glycated haemoglobin] and explore BMI across the life course as mediators of the relationship.

Methods-The Medical Research Council (MRC) National Survey of Health and Development was used to compare partial F-tests of simpler nested life course SEP models corresponding to critical period, accumulation, and social mobility modes with a saturated model. Then, the chosen life course model for each CVD risk factor was adjusted for BMI at age 53 and lifetime BMI (ages 4, 26, 43, and 53 years).

Results-Among women, SEP was generally associated with CVD risk factors in a cumulative manner; while childhood critical period was the prominent model for men. Using the best fitting SEP models, adjustment for BMI at age 53 reduced associations for all outcomes in both genders. Further adjustment for lifetime BMI (4, 26, 43 and 53 years) did not substantially alter most associations (except for triglycerides).

Conclusion-SEP at different points across life influences CVD risk factors differently in men and women.

\section{Keywords}

UK; social class; life course; social mobility; accumulation; cardiovascular risk

\section{Introduction}

Numerous studies have shown that socioeconomic position (SEP) at various points in the life course are associated with cardiovascular disease (CVD) risk, subclinical disease, and

Emily T. Murray, NIA Postdoctoral Fellow in Life Course Epidemiology, MRC Unit for Lifelong Health and Ageing, University College and Royal Free Medical, 33 Bedford Place, London, United Kingdom WC1B 5JU, +44 0207670 5718,

emily.murray@nshd.mrc.ac.uk.

Competing interests: none

Publisher's Disclaimer: This is a PDF file of an unedited manuscript that has been accepted for publication. As a service to our customers we are providing this early version of the manuscript. The manuscript will undergo copyediting, typesetting, and review of the resulting proof before it is published in its final citable form. Please note that during the production process errors may be discovered which could affect the content, and all legal disclaimers that apply to the journal pertain. 
CVD risk factors [1-4]. The mechanisms by which adverse social circumstances over the life course increase risk of cardiovascular outcomes in later life, however, remain unclear. The possible pathways may be better understood by examining at which stages during the life course SEP most strongly influences CVD risk.

Various life course models for SEP have been proposed. The critical (sensitive) period life course model posits that adverse exposures in a specific time window, have an adverse effect on CVD risk development, with no (or less) excess disease risk outside this developmental window [5,6]. Many studies have found associations between childhood SEP and adult CVD risk, which are independent of adult SEP, suggesting that childhood may be a critical period [3, 7-12].

The accumulation model proposes that adverse exposures over the life course cause cumulative damage to biological systems. The accumulation model has been widely supported in the literature with greater time spent in adverse SEP translating to worse CVD outcomes [3]. This has usually been tested by summing or averaging SEP from separate time points to create a measure of life course socioeconomic disadvantage. However, the cumulative score may be significant when SEP at only a single time period is independently associated with the outcome [13].

A few studies have suggested that SEP mobility across the life course has an impact on CVD risk factors [3]. The evidence presented to support this hypothesis is a comparison of stable high, stable low, upward mobility, and downwardly mobile groups showing that the CVD risk of the socially mobile groups are intermediate to the two stable groups. However such a pattern of association could also be the result of an accumulation model.

Hence, support for a particular model has been largely dependent on the a priori hypothesis being tested. Only one study, to our knowledge, has attempted to distinguish between these three SEP life course models in relation to a CVD outcome, incidence of first myocardial infarction [2]. This previous study did not explore potential pathways linking SEP with the outcome.

One potential explanation for how social conditions across the life course translate into differences in CVD health in later life is through a body mass index (BMI) pathway. BMI, as well as being a risk factor for CVD [14, 15], is also associated with other CVD risk factors such as blood pressure (BP) [17] and lipid levels [17] and has been found to be related to both adult and childhood SEP $[18,20]$. Evidence suggests that BMI (and other risk factors for CVD) collected at the same time as SEP do not appear to fully explain the relationship between SEP and CVD incidence [21, 22]. BMI, however, changes across the life course $[23,24]$ so it is possible that more of the association between life course SEP and CVD risk factors could be explained by lifetime BMI, rather than a single adult measure of BMI. Only one study of which we are aware has investigated the role of BMI between SEP and other CVD risk factors [25].

Using data from the Medical Research Council (MRC) National Survey of Health and Development (NSHD), this study uses a structured modelling approach to contrast a series of nested life course SEP models with the saturated model to assess which is most consistent with the data. We apply a method, developed by Mishra et al [13] using BMI in the NSHD as an illustrative example, to now consider other CVD risk factors; blood pressure, lipid levels and glycated haemoglobin. We then investigate whether BMI at age 53 or 'lifetime' $\mathrm{BMI}$ is a stronger mediator of the association between SEP and the other CVD risk factors. 


\section{Methods}

The MRC NSHD is a longitudinal study of health based on a social class stratified sample of 5362 singleton UK births during one week in March 1946. There have been 21 follow-ups of the entire cohort between birth and age 53 years, with the cohort still relatively representative of the British population of the same age [26]. For the most recent completed data collection when the cohort were 53 years old, 3035 respondents (1472 men, 1563 women) were interviewed and examined in their homes by trained research nurses (98\%) or completed a postal questionnaire $(2 \%)$.

\section{Socioeconomic position}

SEP at three time points, represented by occupational social class, were chosen in these analyses to represent different stages of the life course: childhood SEP (S1) [father's occupation when cohort member was age four], young adult SEP (S2) [cohort member's own occupation at 26 years], and later adult SEP (S3) [own occupation at 43 years]. If SEP was missing then the SEP at the closest available age was imputed ( $n=125$ at age 4 from age $7, n=239$ age 26 from 36 years, and $n=241$ age 43 years from age 53 years). Results with and without imputation were similar. Those who had never been in paid work were excluded from the analysis ( $\mathrm{n}=208 ; 126$ women and $65 \mathrm{men}$ ). Occupation was based on the Registrar General's six group classification [27]. At each time point, binary indicators of SEP were used in analysis: non-manual (I and II, III non-manual) $=0$ and manual (III manual, IV and $\mathrm{V})=1$. Of the 4631 with information on SEP at age 4 years, 125 were missing data on young adult SEP, 853 on later adult SEP, and 682 at both years, leaving a total sample for inclusion in analyses of 2971 (1526 men, 1445 women). Those with manual childhood SEP were more likely to be lost to follow-up but differences were small (37\% manual compared to $34 \%$ of non-manual were missing young adult and/or later adult SEP).

\section{Cardiovascular risk factors}

During the home visits when participants were 53 years of age, height and weight were measured according to standardised protocols. BMI was defined as weight $(\mathrm{kg}) / \mathrm{height}(\mathrm{m})^{2}$. Seven additional CVD risk factors were chosen which have been shown to be related to SEP assessed at any period in the life course [3] and BMI [14, 15]: triglycerides (TRIG), glycated haemoglobin (HbA1c), systolic and diastolic blood pressure (SBP/DBP), total cholesterol (CHOL), and low-density and high-density lipoprotein cholesterol (LDL/HDL-C). During the same home visit, blood pressure and non-fasting venous blood samples taken according to standardised protocols, with details of the assessment of CHOL, HDL-C, TRIG, and HbA1c reported elsewhere [28]. LDL was calculated using the Friedewald formula: [CHOL - HDL-C - $(0.45 *$ TRIG $)]$. The second of two blood pressure readings was used in this analysis, taken after 5 minutes of rest with the participant sitting using the validated Omron HEM-705 (Omron Corp., Tokyo, Japan) automated digital oscillometric sphygmomanometer [26].

\section{Covariates}

Additionally, BMI recorded at the same ages as the SEP indicators used in analyses $(4,26$ and 43 years) were used to represent 'lifetime' BMI. This was calculated from measured height and weight at ages 4 and 43 years and from self-reports at age 26 years. Cohort members also reported whether they were taking medications. This information was coded according to the British National Formulary (BNF) Number 40 (2000). Any cohort member taking any drug from the BNF section 2.12 and 2.25 were considered to be on lipid-lowering $(\mathrm{n}=75)$ and anti-hypertensive drugs $(\mathrm{n}=402)$, respectively. 


\section{Statistical Analysis}

This analysis comprises two parts: (1) selection of the most appropriate life course model for each CVD risk factor and (2) investigation of current BMI and 'lifetime' BMI as mediators in the relationship between SEP and the other CVD risk factors.

For section one, a structured modelling approach developed by Mishra et al [13] was used to examine three different hypothesized life course SEP models in relation to each CVD risk factor. The basic premise of the approach is that, given three binary SEP variables, a saturated model would allow all 8 possible SEP trajectories to have a different mean outcome. The saturated model for each outcome was modelled with 3 main effects, all 2 way interactions, and the 3 way interaction, where $\alpha$ is the expected mean for the CVD risk factor outcome for the trajectory where persons were non-manual at all three time points.

It has been demonstrated that by comparing the model fit of a set of nested models corresponding to the accumulation, critical period, and social mobility models - to the saturated model, the nested model that best describes the data can be selected. Here we consider two examples of an accumulation hypothesis: (1) A strict version where it is assumed that, regardless of the time period, the longer a person spends in a manual SEP, the worse the CVD risk and (2) a relaxed model where all time periods are contributing to risk but not necessarily in an equal manner. The critical period hypothesis assumes that SEP influences CVD risk only in a certain time period, irrespective of any other time periods. For purposes of presentation we refer to this as the 'critical period', even though in some cases a sensitive period model may be more realistic. We also consider two examples of social mobility: intra-generational mobility and a general mobility. The intra-generational mobility model hypothesises that downwards mobility between S2 and S3 would be harmful to health, and upwards mobility would be beneficial, irrespective of S1, such that those who remain in a manual social class at both $\mathrm{S} 2$ and $\mathrm{S} 3$ have equal expected means to those who remain in a non-manual social class at both time points. The general mobility model is where all downward and all upward changes are hypothesized to be equally harmful or beneficial. Each life course model specification and constraints are detailed in Appendix 1.

For each risk factor, F-tests were conducted comparing each life course model to the saturated model. Higher p-values represent a better model fit since this indicates that the simpler nested model fit the data as well as the saturated model. When more than one life course model had a p-value greater than 0.05 , we selected the model with the largest $\mathrm{p}$-value where there was a clear difference in p-values. Where two models had similar p-values, we chose the simpler model. We also compared the saturated model with the null model (i.e. $\mathrm{E}(\mathrm{Y})=\alpha$ ). In situations where the null model, and all SEP models, produced a nonsignificant p-value when compared with the saturated model, it was concluded that SEP was not associated with that CVD risk factor and we did not proceed with further analysis. In addition, a sensitivity analyses was conducted substituting SEP at age 53 years in lieu of SEP at 43 years in order to assess whether results were dependent on the age at which the midlife measure of SEP was recorded.

Because of potential differences in associations of SEP with the CVD risk factors between men and women, all analyses are stratified by gender. A constant of 10 and $5 \mathrm{~mm} / \mathrm{Hg}$ to SBP and DBP [29], respectively, and $1.24 \mathrm{mmol}$ per liter (35\%) to LDL [30] was added to those taking specified lipid and blood pressure medications. A log transformation was applied to TRIG and HbA1c to achieve normality.

In the second part of the analyses, each life course SEP model selected in the first part (except those for BMI) was first adjusted for BMI at age 53 and then additionally for 
lifetime BMI (ages 4, 26 and 43). We then examined whether lifetime BMI explained more of the SEP-risk factor association than BMI at 53 years.

\section{Results}

A larger percentage of women than men were in non-manual SEP groups at all three time points [32.6\% vs $29.4 \%$ ], while more men than women experienced a manual SEP at all time points [27.2\% vs $13.0 \%$ ]. Men and women had similar mean values for BMI, HbA1c, CHOL, and LDL; while men had higher TRIG, SBP and DBP and women higher HDL-C. There was heterogeneity of CVD risk factor means by the 8 SEP trajectories with a test for heterogeneity being highly significant for all outcomes except CHOL and LDL [table 1].

For women, the strict accumulation model was the best fitting model for TRIG, SBP, DBP, and HDL-C (p-values: 0.941, 0.658, 0.188, and 0.123). While both the strict and relaxed accumulation models explained the data as well as the saturated model, both p-values were relatively low (strict: 0.063, relaxed: 0.292 ). For simplicity and consistency with the other outcomes, we have chosen the strict accumulation model. For men, the childhood critical period model was the best fitting for BMI and DBP. The relaxed accumulation model had the highest p-value for TRIG and SBP but the p-value for the simpler childhood critical period model was almost as large. Further investigation of the 2 models indicated that the relaxed accumulation model did not fit the data significantly better than the critical period model, and thus the simpler model was selected. For both genders, the relaxed accumulation model had the highest p-value for HbA1c (women 0.537, men 0.814) with the later adult critical period model fitting the data almost as well. Again the more complex model showed no significant improvement in fit and thus the later adult critical period model was chosen. CHOL and LDL in both men and women and HDL-C in men produced non-significant pvalues and non-significant estimates for all models, suggesting that SEP has no effect on these outcomes. Therefore, no further analyses were conducted on these outcomes. Sensitivity analyses substituting SEP at age 53 years in lieu of 43 years altered individual pvalues but did not change basic conclusions in relation to model selection [table 2].

In women, accumulation of manual SEP across the life course was significantly associated with increasing BMI, SBP, DBP and TRIG and decreasing HDL-C. For example, 1-unit increase in SEP score (number of time points 0-3 in manual social class) was associated with an increase in BMI at age 53 of 0.91 (95\% confidence intervals [CI]: 0.66, 1.61) [Table 3]. In men, manual SEP in childhood was associated with a significant increase in mean BMI, SBP, DBP and TRIG. Mean SBP was $6.02 \mathrm{~mm} / \mathrm{Hg}(95 \% \mathrm{CI}$ : 3.38, 8.66) higher in those from a manual SEP in childhood compared with those from a non-manual SEP; similarly the difference was $3.31 \mathrm{~mm} / \mathrm{Hg}(1.74,4.87)$ for DBP. ${ }^{2}$ Manual SEP in later life was associated with a $2.95 \%(1.45,4.44)$ and $2.87 \%(1.44,4.30)$ increase in HbA1c, respectively, for men and women.

Adjustment for BMI at age 53 reduced associations for all outcomes in both genders [Table $3]$, with generally a larger percentage drop in women than men. For example, in women a 1unit increase in accumulated manual SEP was associated with an increase in SBP of 1.59 $\mathrm{mm} / \mathrm{Hg}(0.31,2.86)$ after adjusting for BMI at age 53 , which was a reduction of $32 \%$ (21 to 70 ) in comparison to the crude model. In contrast, men only experienced a drop of $22 \%$ (16 to 36). In contrast, adjustment for BMI at age 53 years reduced estimates for TRIG more in men than women [\% change in estimate from crude model: childhood critical period men: 49\% (31 to 139), accumulation 1-unit women: $34 \%$ (26 to 53) ] but crude estimates were also higher in men. Additional adjustment for lifetime BMI (at ages 4, 26 and 43 years) did not substantially reduce estimates 


\section{Discussion}

Using a new structured approach to distinguish between theoretical life course models of SEP, we found gender differences in the way life course SEP is associated with cardiovascular risk factors. However, within genders results were generally consistent that SEP effects accumulated across the life course in women but were more influential during childhood for men. And while adjustment for BMI at age 53 years reduced the associations between SEP and blood pressure, lipids and glycated haemoglobin, there was no additional impact of adjustment for 'lifetime' BMI.

Our findings are consistent with previous studies that have shown that childhood and adult SEP in women are associated with later life obesity [13, 28, 32-38]. The literature on whether childhood social conditions influence adult obesity in men is less consistent, with only 3 out of 14 studies other than NSHD [33, 35, 37-38] showing childhood SEP effects in men after adjustment for age and adult SEP. However, the likelihood of finding an association in men increased when prospectively collected SEP was utilized, as in our study, suggesting null childhood SEP findings may be a result of recall bias [38].

Similar to findings for BMI, the current study also showed that SBP, DBP, and triglycerides in women were affected by SEP across the life course while for men SEP in childhood was the most pertinent exposure period. Gender-stratified examinations of childhood and adult SEP effects on blood pressures and triglycerides are rare [39] with inconsistent results of SEP effects in men-only [3, 40, 41], women-only [32, 42], and pooled gender [43-45] studies. Almost all previous studies only assessed a single life course model. Most considered a relaxed accumulation model with one childhood and one adult time period [ 3 , $32,39,40,42,44-45$ ] while one study tested a strict accumulation model [43]. Our study improves upon these methods by the addition of SEP exposure at an additional period in the life course and the simultaneous assessment of multiple life course models.

For HbA1c, we found that SEP in time closest to measurement (here being later adulthood) might be more important than other time periods. One explanation is that compared to other CVD risk factors, blood glucose levels do not track so well over the long term [46], reflected in the current test for HbA1c only measuring average blood glucose over the previous 3-11 weeks [47]. Lastly, we did not find an association between SEP at any point in the life course and total cholesterol or LDL. This is consistent with findings from the Northern Swedish Cohort [48], but in contrast to other studies using the accumulation [32] and childhood/adulthood [35] life course models. This could be because, unlike the latter two studies mentioned, we adjusted for cholesterol-lowering medications, which if not accounted for could lead to those in a higher SEP appearing to have lower cholesterol levels because they are more likely to take medications. When analyses were re-fitted with those on medication excluded, p-values for F-tests did not explain the data as well (lower values) but conclusions did not change.

Why SEP effects accumulate over the life course in women but only the effect of childhood SEP is important for men remains unclear. One explanation is that women may be more susceptible than men to BMI change due to events over the life course, such as adolescence [49], pregnancy [50], and menopause [51] and these BMI changes may be socially patterned. Men have been found to be more susceptible to BMI increase only in the period after marriage [52]. There are also clear associations in the NSHD cohort between lower SEP in adulthood and lower fruit and vegetable consumption for women but not men, with low consumption of fruit and vegetables being associated to with higher BMI [58]. Hence, greater SEP differences in diet among women than men may lead to adult SEP being more important in women. BMI throughout the life course is positively associated with blood 
pressure [37, 53-54], and lipid and glycemic profiles [55-57] supporting the role of BMI as a major link between low SEP and poor cardiovascular health; thus explaining the consistency of life course SEP patterns on the risk factors by gender. There is also greater tracking of SEP over the life course in men than women, which may be why childhood SEP is more important than adult SEP in men.

Adjusting for BMI over multiple periods in the life course did not reduce associations between SEP and most CVD risk factors more than adjustments for BMI at 53 years only. Strong tracking of BMI throughout adulthood in NSHD [17] and the small numbers of persons in the general population once overweight or obese whom drop weight categories [59], corroborate evidence that BMI in later life is a good proxy for lifetime BMI.

The application of this novel structured approach to modelling is a strength of the current study, allowing us to examine heterogeneity of life course models by gender and cardiovascular risk factor. However, situations arose where two or more models explained the data as well as the saturated model. Where the p-values, although both non-significant, were clearly very different in size, we chose the model with the best fit. In cases where two models produced similar p-values we investigated the two models in more detail. Unless, there was clear evidence that the more complex model of the two was a better fit than the more parsimonious one, we selected the simpler model. Small numbers of socially mobile individuals also limited our ability to test mobility models. Despite these issues surrounding model selection, our approach is preferable to simply interpreting the results from a single pre-specified model (such as accumulation) without considering the relative merits of alternative models.

Multiple testing may have increased our chances of rejecting a model which fits the data well, but the clear SEP patterns within genders across CVD risk factors suggests that this is unlikely to be the case. Six categories of occupational social class are available in NSHD, but the models become exponentially complex with each increase in the number of categories used and a lack of observations in some SEP trajectories reduce power substantially. Associations of SEP in six categories with the CVD risk factors did however tend to cluster into the manual and non-manual groupings (data not shown).

Using a novel structured approach to modelling, our study finds that SEP at different points across life influences CVD risk factors differently in men and women. This study supports gender-specific interventions, particularly early in life and potentially through BMI pathways, to improve cardiovascular risk profiles in later life.

\title{
Acknowledgments
}

Funding: Medical Research Council; Supported in part by the Intramural Research Program of the National Institute on Aging, NIH

\section{Appendix}

\author{
Appendix 1 \\ Model specification and constraints for given life course \\ models
}

\begin{tabular}{lll}
\hline & Life-course model specification & Constraints \\
\hline Saturated model & $\alpha+\beta_{1} S_{1}+\beta_{2} S_{2}+\beta_{3} S_{3}+\theta_{12} S_{1} S_{2}+\theta_{13} S_{1} S_{3}+\theta_{23} S_{2} S_{3},+\theta_{123} S_{1} S_{2} S_{3}$ & \\
No effect & $\alpha$ &
\end{tabular}




\begin{tabular}{lll}
\hline & Life-course model specification & Constraints \\
\hline Accumulation, strict & $\alpha+\beta_{1}\left(S_{1}+S_{2}+S_{3}\right)$ & \\
Accumulation, relaxed & $\alpha+\beta_{1} S_{1}+\beta_{2} S_{2}+\beta_{3} S_{3}$ & \\
Critical Period & & \\
$\quad$ Childhood & $\alpha+\beta_{1} S_{1}$ & \\
Early adult & $\alpha+\beta_{2} S_{2}$ & \\
Later adult & $\alpha+\beta_{3} S_{3}$ & $\theta_{23}=-\left(\beta_{2}+\beta_{3}\right)$ \\
Adult social mobility & $\alpha+\beta_{2} S_{2}+\beta_{3} S_{3}+\theta_{23} S_{2} S_{3}$ & $\beta_{2}=\left(\beta_{1+} \beta_{3}\right), \& \theta_{12}=$ \\
Any social mobility & $\alpha+\beta_{1} S_{1}+\beta_{2} S_{2}+\beta_{3} S_{3}+\theta_{12} S_{1} S_{2}+\theta_{23} S_{2} S_{3}$, & $\theta_{23}=-\beta_{2}$ \\
\hline
\end{tabular}

\section{References}

1. Carson AP, Rose KM, Catellier DJ, Kaufman S, Wyatt SB, Diez-Roux AV, et al. Cumulative socioeconomic status across the life course and subclinical atherosclerosis. Ann Epidemiol. 2007; 17(4):296-303. [PubMed: 17027292]

2. Hallqvist J, Lynch J, Bartley M, Lang T, Blane D. Can we disentangle life course processes of accumulation, critical period and social mobility? An analysis of disadvantaged socio-economic positions and myocardial infarction in the Stockholm heart epidemiology program. Soc Sci Med. 2004; 58(8):1555-62. [PubMed: 14759698]

3. Pollitt RA, Rose KM, Kaufman JS. Evaluating the evidence for models of life course socioeconomic factors and cardiovascular outcomes: a systematic review. BMC Public Health. 2005; 5:7. [PubMed: 15661071]

4. Singh-Manoux A, Ferrie JE, Chandola T, Marmot M. Socioeconomic trajectories across the life course and health outcomes in midlife: evidence for the accumulation hypothesis? Int J Epidemiol. 2004; 33(5):1072-1079. [PubMed: 15256527]

5. Kuh D, Ben-Shlomo Y, Lynch J, Hallqvist J, Power C. Life course epidemiology. J Epidemiol Community Health. 2003; 57(10):778-783. [PubMed: 14573579]

6. Barker DJ. Fetal origins of coronary heart disease. BMJ. 1998; 311(6998):171-174. [PubMed: 7613432]

7. Claussen B, Davey-Smith G, Thelle D. Impact of childhood and adulthood socioeconomic position of cause specific mortality: the Oslo Mortality Study. J Epidemiol Community Health. 2003; 57(1): 40-45. [PubMed: 12490647]

8. Kaplan GA, Keil JE. Socioeconomic factors and cardiovascular disease: a review of the literature. Circulation. 1993; 88:1973-1998. [PubMed: 8403348]

9. Gliksman MD, Kawachi I, Hunter D, Colditz GA, Manson JE, Stampfer MJ. Childhood socioeconomic status and risk of cardiovascular disease in middle aged US women: a prospective study. J Epidemiol Community Health. 1995; 49(1):10-15. [PubMed: 7706992]

10. Lynch JW, Kaplan GA, Cohen RD, Kauhanen J, Wilson TW, Smith NL, et al. Childhood and adult socioeconomic status as predictors of mortality in Finland. Lancet. 1994; 343(8896):524-527. [PubMed: 7906766]

11. Lamont D, Parker L, White M, Unwin N, Bennett SM, Cohen M, et al. Risk of cardiovascular disease measured. BMJ. 2000; 320(7230):273-278. by. [PubMed: 10650022]

12. Smith GD, Hart C. Life-course socioeconomic and behavioural influences on cardiovascular disease mortality: the collaborative study. Am J Public Health. 2002; 92(8):1295-1298. [PubMed: 12144987]

13. Mishra G, Nitsch D, Black S, De Stavola B, Kuh D, Hardy R. A structured approach to modelling the effects of binary exposure variables over the life course. Int J Epidemiol. 2009; 38(2):528-537. [PubMed: 19028777]

14. Douketis JD, Sharma AM. Obesity and cardiovascular disease: pathogenic mechanisms and potential benefits of weight reduction. Sem Vasc Med. 2005; 5(1):25-33. 
15. Perez Perez A, Ybarra Munoz J, Blay Cortes V, De Pablos Velasco P. Obesity and cardiovascular disease. Public Health Nutr. 2007; 10(10A):1156-1163. [PubMed: 17903325]

16. Wills AK, Hardy RJ, Black S, Kuh D. Trajectories of overweight and body mass index in adulthood and blood pressure at age 53: the 1946 British birth cohort study. J Hypertens. 2009; 28:679-686. [PubMed: 20042875]

17. Pataky Z, Bobbioni-Harsch E, Hadengue A, Carpentier A, Golay A. Enlarged waist circumference and cardiovascular risk factors. Rev Med Suisse Romande. 2009; 5(196):671-672. 674-675.

18. Barkley GS. Factors influencing health behaviors in the National Health and Nutritional Examination Survey, III (NHANES III). Soc Work Health Care. 2008; 46(4):57-79. [PubMed: 18589564]

19. Power C, Parsons T. Nutritional and other influences in childhood as predictors of adult obesity. Proc Nutr Soc. 2000; 59(2):267-272. [PubMed: 10946795]

20. Schaap MM, Kunst AE. Monitoring of socio-economic inequalities in smoking: learning from the experiences of recent scientific studies. Public Health. 2009; 123(2):103-109. [PubMed: 19147163]

21. McFadden E, Luben R, Wareham N, Bingham S, Khaw KT. Occupational social class, risk factors and cardiovascular disease incidence in men and women: a prospective study in the European Prospective Investigation of Cancer and Nutrition in Norfolk (EPIC-Norfolk) cohort. Eur J Epidemiol. 2008; 23:449-458. [PubMed: 18509727]

22. Woodward M, Shewry MC, Smith WC, Tunstall-Pedoe H. Social status and coronary heart disease: results from the Scottish Heart Health Study. Prev Med. 1992; 21(1):136-148. [PubMed: 1738765]

23. Ostbye T, Malhotra R, Landerman LR. Body mass trajectories through adulthood: results from the National Longitudinal Survey of Youth 1979 Cohort (1981-2006). Int J Epidemiol. 2010:1-11. Epub 2010 Sept 5. [PubMed: 20175264]

24. Li L, Hardy R, Kuh D, Lo Conte R, Power C. Child-to-adult body mass index and height trajectories: a comparison of 2 British birth cohorts. Am J Epidemiol. 2008; 168(9):1008-1015. [PubMed: 18801885]

25. Gustafsson PE, Persson M, Hammarstrom A. Life Course Origins of the Metabolic Syndrome in Middle-Aged Women and Men: The Role of Socioeconomic Status and Metabolic Risk Factors in Adolescence and Early Adulthood. Ann Epidemiol. 2011; 21(2):103-110. [PubMed: 21184951]

26. Wadsworth ME, Butterworth SL, Hardy RJ, Kuh DJ, Richards M, Langenberg C, et al. The life course prospective design: an example of benefits and problems associated with study longevity. Soc Sci Med. 2003; 57(11):2193-2205. [PubMed: 14512249]

27. Galobardes B, Shaw M, Lawlor DA, Lynch JW, Davey Smith G. Indicators of socioeconomic position (part 2). J Epidemiol Community Health. 2006; 60(2):95-101. [PubMed: 16415256]

28. Langenberg C, Kuh D, Wadsworth EJ, Brunner E, Hardy R. Social circumstances and education: Life course origins of social inequalities in metabolic risk in a Prospective National Birth Cohort. Am J Public Health. 2006; 96:2216-2221. [PubMed: 17077402]

29. Cui J, Hopper JL, Harrap SB. Antihypertensive treatments obscure familial contributions to blood pressure variation. Hypertension. 2003; 41(2):207-210. [PubMed: 12574083]

30. Nissen SE, Tuzcu EM, Schoenhagen P, Crowe T, Sasiela WJ, Tsai J, et al. Statin therapy, LDL cholesterol, C-reactive protein, and coronary artery disease. New Eng J Med. 2005; 352(1):29-38. [PubMed: 15635110]

31. Brunner E, Shipley MJ, Blane D, Smith GD, Marmot GD. When does cardiovascular risk start? Past and present socioeconomic circumstances and risk factors in adulthood. J Epidemiol Community Health. 1999; 53(12):757-764. [PubMed: 10656084]

32. Heslop P, Smith GD, Macleod J, Hart C. The socioeconomic position of employed women, risk factors, and mortality. Soc Sci Med. 2001; 53(4):477-485. [PubMed: 11459398]

33. Kittleson MM, Meoni LA, Wang NY, Chu AY, Ford DE, Klag MJ. Association of childhood socioeconomic status with subsequent coronary heart disease in physicians. Arch Int Med. 2006; 166(21):2356-2361. [PubMed: 17130389] 
34. Langenberg C, Hardy R, Kuh D, Brunner E, Wadsworth M. Central and total obesity in middle aged men and women in relation to lifetime socioeconomic status: evidence from a national birth cohort. J Epidemiol Community Health. 2003; 57(10):816-822. [PubMed: 14573589]

35. Lawlor DA, Batty D, Morton SMB, Clark H, Macintyre S, Leon DA. Childhood socioeconomic position, educational attainment, and adult cardiovascular risk factors: the Aberdeen children of the 1950s cohort study. Am J Public Health. 2005; 95:1245-1251. [PubMed: 15983276]

36. Mishra GD, Malik NS, Paul AA, Wadsworth MEJ, Bolton-Smith C. Childhood and adult dietary vitamin E intake and cardiovascular risk factors in mid-life in the 1946 British Birth Cohort. Eur J Clin Nutr. 2003; 57:1418-1425. [PubMed: 14576755]

37. Power C, Manor O, Matthews S. Child to adult socioeconomic conditions and obesity in a national cohort. Int J Obes. 2003; 27:1081-1086.

38. Senese LC, Almeida ND, Fath AK, Smith BT, Loucks EB. Associations between childhood socioeconomic position and adulthood obesity. Epidemiol Rev. 2009; 31:21-51. [PubMed: 19648176]

39. Parker L, Lamont DW, Unwint N, Pearce MS, Bennett SMA, Dickinson HO, White M, Mathers JC, Alberti KGMM, Craft AW. A lifecourse study of risk for hyperinsulinaemia, dislipidaemia and obesity (the central metabolic syndrome) at age 49-51 years. Diabet Med. 2003; 20:406-415. [PubMed: 12752491]

40. Blane D, Hart CL, Smith GD, Gillis CR, Hole DR, Hawthorne VM. Association of cardiovascular disease risk factors with socioeconomic position during childhood and during adulthood. BMJ. 1996; 313(7070):1434-1438. [PubMed: 8973230]

41. Smith GD, Hart C, Hole D. Adverse socioeconomic conditions in childhood and cause specific adult mortality: prospective observational study. BMJ. 1998; 316:1631-1635. [PubMed: 9603744]

42. Lawlor DA, Davey Smith G, Ebrahim S. Life course influences on insulin resistance: findings from the British Women's Heart and Health Study. Diabetes Care. 2003; 26:97-103. [PubMed: 12502664]

43. Smith GD, Hart C, Blane D, Gillis C, Hawthorne V. Lifetime socioeconomic position and mortality: prospective observational study. BMJ. 1997; 314:547-552. [PubMed: 9055712]

44. Poulton R, Caspi A, Milne BJ, Thomson WM, Taylor A, Sears MR, Moffitt TE. Association between children's experience of socioeconomic advantage and adult health: a life-course study. Lancet. 2002; 360:1640-1645. [PubMed: 12457787]

45. Lawlor DA, Ebrahim S, Davey-Smith G. Socioeconomic position in childhood and adulthood and insulin resistance: cross-sectional survey using data from British women's heart and health study. BMJ. 2002; 325:805. [PubMed: 12376440]

46. Eisenmann JC, Welk GJ, Wickel EE, Blair SN. Stability of variables associated with the metabolic syndrome from adolescence to adulthood: the Aerobics Center Longitudinal Study. Am J Hum Biol. 2004; 16(6):690-696. [PubMed: 15495227]

47. Little RR, Sacks DB. HbA1c: how do we measure it and what does it mean? Curr Opin Endocrinol Diabetes Obes. 2009; 16(2):113-118. [PubMed: 19300091]

48. Gustafsson PE, Janler U, Theorell T, Westerlund H, Hammarstrom A. Fetal and life course origins of serum lipids in mid-adulthood: results from a prospective cohort study. BMC Public Health. 2010; 10:484. [PubMed: 20712860]

49. Serdula MK, Ivery D, Coates RJ, Freedman DS, Williamson DF, Byers T. Do obese children become obese adults? A review of the literature. Prev Med. 1993; 22(2):167-177. [PubMed: 8483856]

50. Williamson DF, Madans J, Pamuk E, Flegal KM, Kendrick JS, Serdula MK. A prospective study of childbearing and 10-year weight gain in US white women 25 to 45 years of age. Int J Obes Rel Metab Disord. 1994; 18(8):561-569.

51. Wing RR, Matthews KA, Kuller LH, Meilahn EN, Plantinga PL. Weight gain at the time of menopause. Arch Intern Med. 1991; 151(1):97-102. [PubMed: 1985614]

52. Sobal J, Rauschenbach BS, Frongillo EA. Marital status, fatness and obesity. Soc Sci Med. 1992; 35(7):915-923. [PubMed: 1411692] 
53. Kivimaki M, Lawlor DA, Smith GD, Keltikangas-Jarvinen L, Elovainio M, Vahtera J, et al. Early socioeconomic position and blood pressure in childhood and adulthood: the Cardiovascular Risk in Young Finns Study. Hypertension. 2006; 47(1):39-44. [PubMed: 16330678]

54. Whincup, PH.; Cook, DG.; Geleijnse, JM. A life course approach to blood pressure. In: Kuh, D.; Ben-Shlomo, Y., editors. A life course approach to chronic disease epidemiology. Oxford, UK: Oxford University Press; 2004. p. 218-239.

55. Lloyd-Jones DM, Liu K, Colangelo LA, Yan LL, Klein L, Loria CM. Consistently stable or decreased body mass index in young adulthood and longitudinal changes in metabolic syndrome components: the Coronary Artery Risk Development in Young Adults Study. Circulation. 2007; 115(8):1004-1011. [PubMed: 17283263]

56. Nguyen QM, Srinivasan SR, Xu JH, Chen W, Berenson GS. Distribution and cardiovascular risk correlates of haemoglobin A(1c) in nondiabetic younger adults: the Bogalusa Heart Study. Metabolism. 2008; 57(11):1487-1192. [PubMed: 18940383]

57. Siervogel RM, Wisemandle W, Maynard LM, Guo SS, Chumlea WC, Towne B. Lifetime overweight status in relation to serial changes in body composition and risk factors for cardiovascular disease: The Fels Longitudinal Study. Obes Res. 2000; 8(6):422-430. [PubMed: 11011908]

58. Mishra GD, McNaughton SA, Bramwell GD, Wadsworth ME. Longitudinal changes in dietary patterns during adult life. Br J Nutr. 2006; 96(4):734-744. 


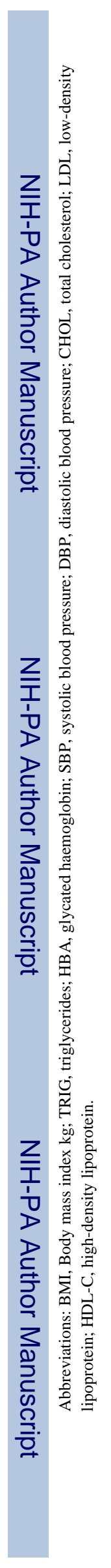




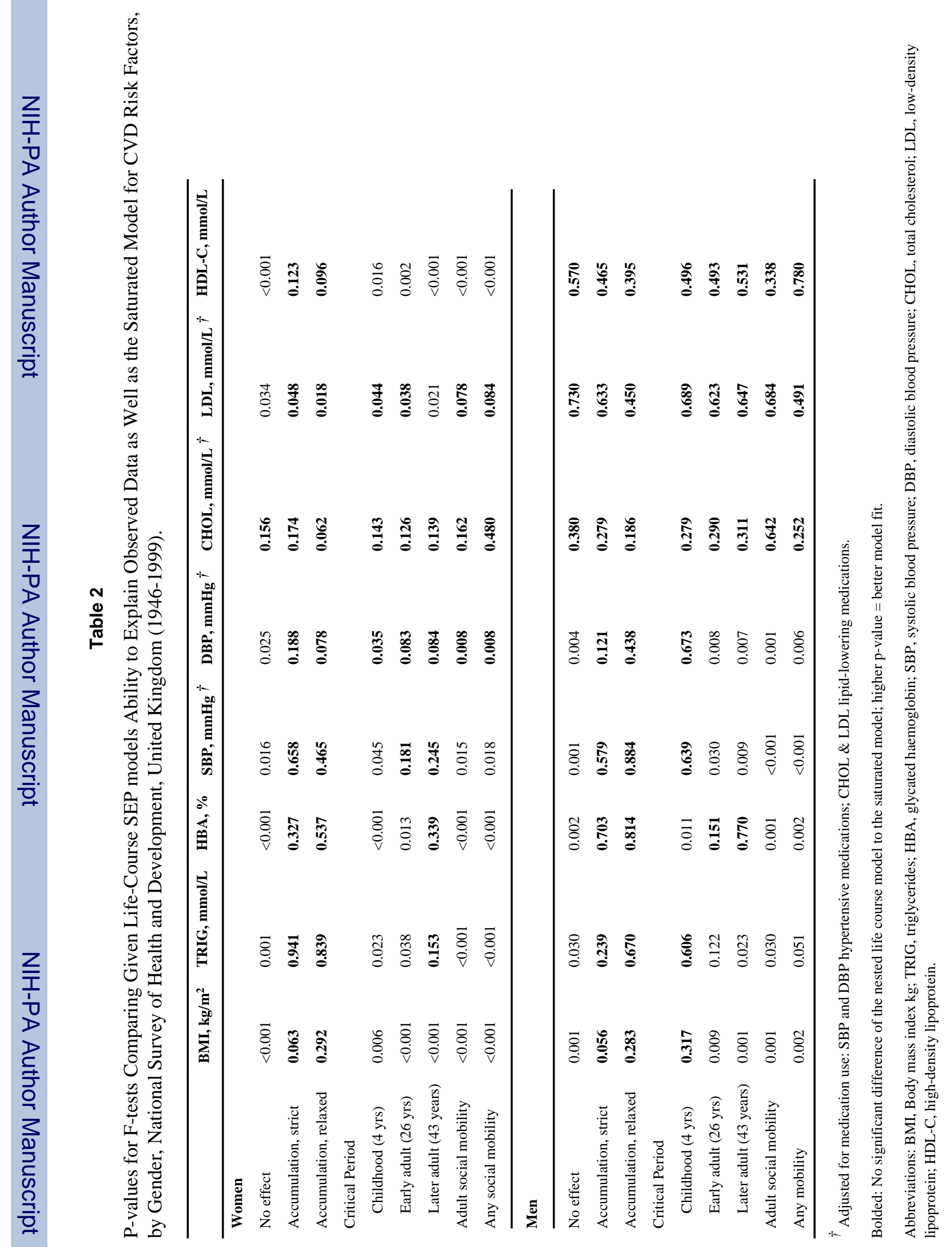




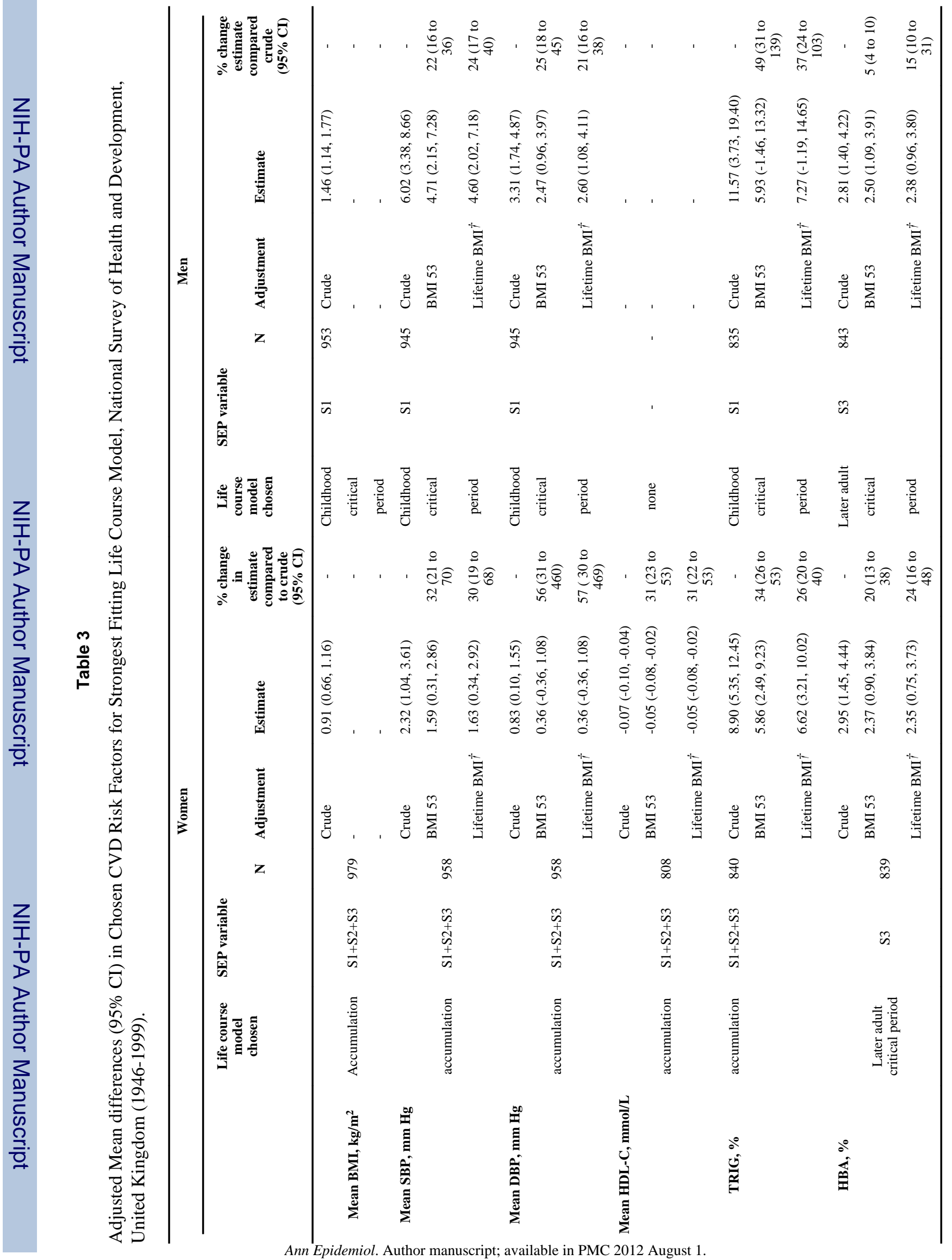




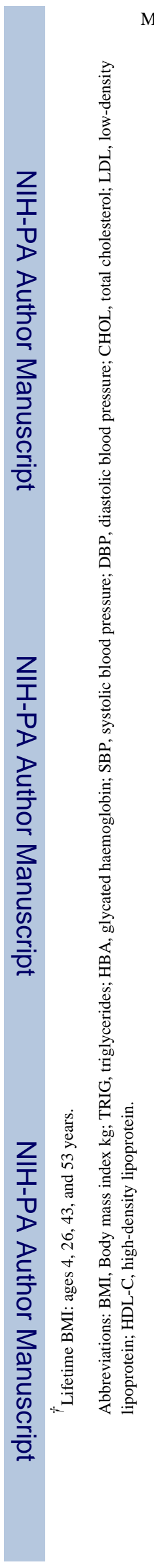

Murray et al.

Page 16

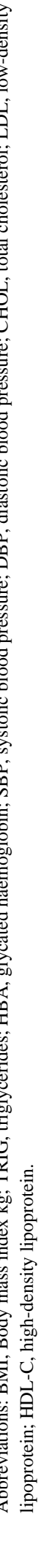

Ann Epidemiol. Author manuscript; available in PMC 2012 August 1. 